\title{
The clinical and molecular spectrum of galactosemia in patients from the Cape Town region of South Africa Howard Henderson*1, Felicity Leisegang1, Ruth Brown ${ }^{1}$ and Brian Eley ${ }^{2}$
}

\author{
Address: ${ }^{1}$ Department of Chemical Pathology and School of Child and Adolescent Health, Red Cross Children's Hospital, University of Cape \\ Town, Cape Town, South Africa and ${ }^{2}$ Dept of Pediatrics, and School of Child and Adolescent Health, Red Cross Children's Hospital, University of \\ Cape Town, Cape Town, South Africa \\ E-mail: Howard Henderson* - henders@ich.uct.ac.za; Felicity Leisegang - leisegan@ich.uct.ac.za; Ruth Brown - Rbrown@pawc.wcape.gov.za; \\ Brian Eley - beley@ich.uct.ac.za \\ ${ }^{*}$ Corresponding author
}

Published: 2 September 2002

BMC Pediatrics 2002, 2:7
Received: 19 July 2002

Accepted: 2 September 2002

This article is available from: http://www.biomedcentral.com/I47I-243I/2/7

(c) 2002 Henderson et al; licensee BioMed Central Ltd. This article is published in Open Access: verbatim copying and redistribution of this article are permitted in all media for any non-commercial purpose, provided this notice is preserved along with the article's original URL.

\begin{abstract}
Background: The objective of this study was to document the clinical, laboratory and genetic features of galactosemia in patients from the Cape Town metropolitan region.

Methods: Diagnoses were based on thin layer chromatography for galactosuria/galactosemia and assays of erythrocyte galactose-I-phosphate uridyltransferase (GALT) and galactokinase activities. Patients were screened for the common SI35L and Q I88R transferase gene mutations, using PCRbased assays. Screening for the SI35L mutation in black newborns was used to estimate the carrier rate for galactosemia in black South Africans.

Results: A positive diagnosis of galactosemia was made in 17 patients between the years 1980 to 200I. All had very low or absent galactose-I-phosphate uridyltransferase (GALT) activity, and normal galactokinase levels. The mean age at diagnosis was 5.1 months (range 4 days to 6.5 months). A review of 9 patients showed that hepatomegaly (9/9), and splenomegaly, failure to thrive, developmental delay, bilateral cataracts (6/9) were the most frequent features at diagnosis. Six had conjugated hyperbilirubinemia. Four experienced invasive $E$. coli infection before diagnosis. Ten patients were submitted to DNA analysis. All 4 black patients and 2 of mixed extraction were homozygous for the SI35L allele, while all 3 white patients were homozygous for the QI $88 \mathrm{R}$ allele. The remaining patient of mixed extraction was heterozygous for the Q $188 \mathrm{R}$ allele. The estimated carrier frequency of the SI35L mutation in 725 healthy black newborns was $1 / 60$.

Conclusions: In the absence of newborn screening the delay in diagnosis is most often unacceptably long. Also, carrier frequency data predict a galactosemia incidence of approximately I/14 400 for black newborns in the Cape Metropole, which is much higher than the current detection rate. It is thus likely that many patients go undetected.
\end{abstract}

\section{Background}

Galactosemia is an autosomally inherited disorder of galactose metabolism, which occurs as a consequence of a deficiency of one of three principal enzymes involved in the metabolism of galactose, through its conversion to glucose. These enzymes are galactokinase (GALK; 
EC2.7.1.6), galactose-1-phosphate uridyltransferase (GALT; EC2.7.7.10) and uridine-diphosphate galactose-4' epimerase (GALE; EC 5.1.3.2). The most common deficiency in all communities is that of the transferase enzyme, and it is this enzyme deficiency that underlies "classical galactosemia"[1].

Transferase-deficiency galactosemia usually presents in the neonatal period with failure to thrive, feeding difficulties and prolonged conjugated hyperbilirubinemia. The condition can be fatal if a lactose / galactose restricted diet is not introduced. Presentation later in life may involve hepatic cirrhosis, cataracts, ataxia, speech defects, mental retardation and premature ovarian failure [2]. Laboratory diagnosis usually proceeds through a demonstration of galactosuria, an elevated erythrocyte galactose-1-phosphate concentration, and reduced / absent erythrocyte GALT activity.

The laboratories of the Red Cross Children's Hospital have functioned as an African (Zimbabwe), National and Western Cape Provincial reference centre for galactosemia for the past two decades. Of the 41 positive cases recorded, 29 (71\%) have been black, with the majority of these patients being born in Zimbabwe. While other laboratories in South Africa also offer galactosemia diagnostics, virtually all cases investigated in Cape Town and the broader Cape Metropole region, have involved the Red Cross Children's Hospital laboratories. All patients were evaluated with specific red-cell enzyme assays. More recently, patients have been screened for common mutations in the GALT gene. The Cape Metropole surrounds Cape Town to the east, north and west, and is home to 3.15 million people of diverse ancestries.

This report documents the presenting clinical and laboratory features of galactosemia in patients from the Cape Metropole and describes a rapid polymerase chain reaction (PCR) assay for identifying the S135L mutation. This assay was successfully used to estimate the carrier frequency of the S135L mutation in black newborn babies in the region.

\section{Methods \\ Patients}

All children diagnosed with galactosemia in the Cape Metropole by the Chemical Pathology laboratories at Red Cross Children's Hospital between 1980 and 2001 were identified from the service database. Hospital case records were retrospectively reviewed to establish the clinical and laboratory features present at the time of diagnosis.

\section{Galactosuria/galactosaemia}

Galactose concentrations in urine and serum/plasma were examined by thin layer chromatography (TLC). Aliquots
$(5 \mu \mathrm{l})$ were spotted onto Silica gel plates (Merck Silical Gel 60), developed twice in butanol:acetone:water (5:4:1) and visualised using the aniline-diphenylamine Phosphate reagent [3].

\section{Enzyme assay}

EDTA blood ( $5 \mathrm{ml}$ ) was drawn for plasma TLC, and determination of erythrocyte transferase and kinase activities. Transferase activity is given as U/gm Hb ( 1 unit $=1 \mu \mathrm{mol}$ UDPG /hr). Both enzyme assays were carried out on cell lysates, according to established methods [4],[5].

\section{DNA testing}

All DNA testing was approved by the Ethics Research Committee of the University of Cape Town. Mutation analysis was only carried out for the Q188R [6] and S135L $[7,8]$ mutations in the GALT gene underlying classical (G/ $\mathrm{G})$ galactosemia. These mutations are commonly reported in patients of Caucasian, and Negroid ancestries, respectively. Both mutations were detected by PCR using blood spots prepared from venous or umbilical cord blood samples. The latter samples were obtained from midwife obstetric units and were anonymised by removing all identifying tags. Genomic DNA extracts suitable for PCR were prepared from punched discs $(3 \mathrm{~mm})$, which were treated with methanol $(200 \mu \mathrm{l})$, air-dried and then boiled in $50 \mu \mathrm{l}$ water. Aliquots of $5 \mu \mathrm{l}$ were used for each PCR determination, in a total volume of $25 \mu \mathrm{l}$. A hot start or the use of antibody inhibited Taq polymerase was required to obtain consistent and reliable amplification.

Transferase-deficiency galactosemia patients were screened for the common S135L mutation using a novel restriction PCR assay where a mismatch forward primer (P1) was used to introduce a Psh $\mathrm{Al}$ cutting site (GAC $\mathrm{N}_{4}$ GTC) into the PCR product derived from the normal allele; P2 was used as the reverse primer. Large scale screening of the cord blood samples was carried out using a less costly PCR assay where amplification refractory mutation system (ARMS) primers were used, these being forward primers $\mathrm{P} 3$ and $\mathrm{P} 4$. These primers selectively amplified either the mutant or the normal sequence of the GALT allele; two tubes were therefore set up for each cord blood sample, with P2 again being the reverse primer. The sequences of the "in house" primers used in these assays are as follows:

P1, 5'-ATGTGCTTCCGACCCTGGTC-3';

P2, 5'-GGAAGGGGCGACCTCACAAAC-3';

P3, 5'-TCATGTGCTTCCACCCCTGTTC-3';

P4, 5'-TCATGTGCTTCCACCCCTGTTT-3'. 
Table I: Clinical features at diagnosis

\begin{tabular}{ll}
\hline Clinical feature & Number $\mathbf{N}=\mathbf{9}$ \\
\hline & \\
\hline Hepatomegaly & 9 \\
Splenomegaly & 6 \\
Failure to thrive & 6 \\
Developmental delay & 6 \\
Bilateral cataracts & 6 \\
Jaundice & 5 \\
Underweight-for-age & 5 \\
Stunting & 4 \\
Vomiting & 2 \\
Ascites & 1 \\
Diarrhoea & 1 \\
\end{tabular}

The common Caucasian mutation, Q188R was detected by PCR amplification of exon 6 and digestion with the restriction enzyme Нpa II as described [9].

\section{Results \\ Patients}

Between 1980 and 2001, 17 patients from the Cape Metropole were diagnosed with galactosemia; this cohort included one sib pair. The ancestries of these patients were recorded as Black (being of Negroid extraction), Mixed (admixture of European, Negroid and East-Indian extraction), and White (of European extraction). The mean age at diagnosis was 5.1 months (range: 4 days to 6.5 months), with the male to female ratio being $1.6: 1$. Eight children $(47 \%)$ were black, $3(18 \%)$ were white and 6 (35\%) were of mixed ancestry. During the period 1980 to 1989 nine children were diagnosed, from 1990 to 1999 six children were diagnosed and during the last 2 years two were diagnosed.

The clinical notes of 9 patients were available for review. These showed hepatomegaly (9/9), and splenomegaly, failure to thrive, developmental delay, bilateral cataracts $(6 / 9)$ to be the most frequently encountered features at the time of diagnosis (Table 1). One child had a family history of galactosemia on presentation. Four experienced invasive E. coli infection before diagnosis. Six had conjugated hyperbilirubinemia, 5 elevated plasma alanine aminotransferase concentration, 8 elevated alkaline phosphatase concentration and 7 reduced plasma albumin concentration.

\section{Laboratory findings}

All patients presented with galactosuria and very low or absent transferase activity, giving a mean and SD of $2.2 \pm$ $1.12 \mathrm{U} / \mathrm{gm} \mathrm{Hb}(\mathrm{n}=17$; range $0-3.8)$ and normal galac- tokinase levels. Where possible, blood was also obtained from the parents to establish transferase levels in obligate heterozygotes. The range of activities in these subjects $(\mathrm{n}=$ 12 ; mean plus $\mathrm{SD}=12.3 \pm 3.55 \mathrm{U} / \mathrm{gm} \mathrm{Hb}$; range $6.8-$ 18.2) was distinct from that of the affected cohort but did show significant overlap with normals $(n=23$; mean plus $\mathrm{SD}=31.8 \pm 12.9 \mathrm{U} / \mathrm{gm} \mathrm{Hb}$; range 12.3-65)

\section{Mutation analysis}

Blood spots were available from 10 of the 17 referred patients, and all were screened using the S135L and Q188R PCR-based assays. All 4 black patients and 2 patients of mixed extraction were homozygous for the $5135 \mathrm{~L}$ allele, while all 3 white patients were homozygous for the Q188R allele. The remaining patient of mixed extraction was heterozygous for the Q188R allele and was presumed to be a compound heterozygote for some other, as yet unidentified mutation in the GALT gene (Table 2).

\section{Carrier frequency of the SI35L mutation}

Each of the 725 umbilical cord blood samples generated a PCR product with the Amplification Refractory Mutation System (ARMS) primers specific for the normal sequence at codon 135 of the GALT gene, indicating efficient extraction of intact DNA template. A total of 12 cord bloods yielded PCR product with the ARMS primer for the mutant sequence. Carrier status for these individuals was confirmed by coupling a repeat ARMs primer PCR with the restriction PCR assay. These findings yielded a carrier frequency of $1 / 60$ (95\% CI; 0.0081 - 0.022).

\section{Discussion}

Galactosemia, an inborn error of metabolism, has been evident in the South African population for many decades. Only a few reports however, have dealt with the demographics, and clinical / laboratory findings in affected individuals [10],[11],[12]. The recent unravelling of the molecular genetics of galactosemia [for review see [13]] has prompted a re-examination of this condition in South Africa. This manuscript details the clinical, laboratory and molecular genetic findings of patients from the Cape Metropolitan region.

The diagnosis of galactosemia is usually made early in the neonatal period [1]. In the present study, the mean age at diagnosis of 5.1 months is indicative of considerable delays in detection. While obvious reasons for this are not apparent, a lack of awareness is likely to be an important consideration. In summary then, it is important that the diagnosis be considered in young children with suggestive features including persistent hypoglycaemia, failure to thrive, feeding difficulties, prolonged conjugated hyperbilirubinemia, hepatomegaly, ascites, invasive E. coli infections, neurodevelopmental delay and galactosuria. Another consideration is that mild clinical phenotypes 
Table 2: Presentation data, GALT activity and mutation type of patients with galactosemia

\begin{tabular}{|c|c|c|c|c|c|}
\hline Patient & Year of diagnosis & $\begin{array}{c}\text { Age at Dx } \\
\text { (months) }\end{array}$ & Race & GALT activity $^{*}$ & Mutation \\
\hline 1 & 1980 & 0.1 & W & 3.0 & Q188R / Q188R \\
\hline 2 & 1983 & 0.1 & W & 1.6 & Q188R / Q188R \\
\hline 3 & 1984 & - & $?$ & 2.4 & nd \\
\hline 4 & 1984 & 6.5 & B & 0.2 & nd \\
\hline 5 & 1985 & 4 & B & 4.2 & SI35L / SI35L \\
\hline 6 & 1985 & 14.5 & B & 2.4 & nd \\
\hline 7 & 1985 & - & B & 2.7 & nd \\
\hline 8 & 1986 & 2.5 & $M$ & 3.5 & nd \\
\hline 9 & 1987 & 7 & B & 0.0 & nd \\
\hline 10 & 1990 & 2 & B & 1.2 & SI35L / S135L \\
\hline 11 & 1991 & 0.3 & $M$ & 0.0 & Q188R /? \\
\hline 12 & 1991 & 4 & $M$ & 1.4 & nd \\
\hline 13 & 1995 & - & $M$ & 3.8 & SI35L / SI35L \\
\hline 14 & 1996 & 16 & B & 0.8 & SI35L / SI35L \\
\hline $15^{* *}$ & 1996 & - & B & 3.5 & SI35L / SI35L \\
\hline 16 & 1998 & 6 & B & 2.9 & SI35L / S135L \\
\hline 17 & 2001 & 2 & $M$ & 2.2 & SI35L / SI35L \\
\hline 18 & 2001 & 7 & W & 2.2 & $\mathrm{Q} 188 \mathrm{R} / \mathrm{Q} 188 \mathrm{R}$ \\
\hline
\end{tabular}

* Normal range of GALT activity: 12.5 to $65.0 \mathrm{U} / \mathrm{gm}$ of $\mathrm{Hb}(\mathrm{I} \mathrm{U}=\mathrm{I} \mu \mathrm{mol} \mathrm{UDPG} / \mathrm{hr}){ }^{* *}$ Clinical data unavailable $\mathrm{B}=\mathrm{Black}(\mathrm{Negroid}), \mathrm{M}=\mathrm{Mixed}$ ancestry, $\mathrm{W}=$ European ancestry

may delay presentation. In contrast to the Q188R mutation, the S135L mutation is associated with a better clinical outcome [8].

Treatment of Galactosemia involves complete elimination of dietary lactose / galactose. This limits death associated with $E$. coli infection, reverses growth failure and cataract formation, and prevents severe liver disease. Unfortunately, dietary modification does not moderate the risk of long-term central nervous system dysfunction such as speech defects, mental retardation and ataxia nor premature ovarian failure [2],[14],[15].

The GALT genotypes defined in our patient cohort conform to reports from other countries, where the Q188R and S135L mutations are commonly encountered in classical galactosemia. Allele prevalences of $60-70 \%$ have been found for Q188R in Caucasian patients $[16,17]$, while prevalences of $48 \%$ [8] and $91 \%$ [12], have been reported in African American and in African Negroid patients, respectively. Of the 18 GALT alleles, from the 9 unrelated patients in our study, only one did not carry either of these two mutations. Although our sample size is small, this finding holds great promise for the genetic diagnosis of galactosemia in South Africa, as these two mutations alone will account for the bulk of the galactosemia burden. While other prominent mutations have been described, such as the K285N substitution in East / Central
Europe, the majority of the mutations listed in the GALT database (URL: [http://www.ich.bris.ac.uk/galtdb/]) are rare and likely to be family specific. All 10 of the black GALT alleles examined in our study carried the S135L amino acid substitution. This finding confirms the earlier report of a $>90 \%$ association of this mutation with GALT alleles in black South Africans [12]. In contrast, the two unrelated white patients were both homozygous for the Q188R mutation. It is not surprising therefore, that 5 of the 6 GALT alleles from patients of mixed ancestry, manifest one of these two mutations.

The true incidence of galactosemia in South Africa remains difficult to define. Newborn screening and other surveillance programmes in Europe and North America have established newborn rates of $1 / 30000$ to $1 / 50000$ in Caucasians $[18],[19,20]$. Similar newborn incidences are probably present in white South Africans. A reliable figure can now be applied to black South Africans as our cord-blood screening programme for the S135L mutation in the GALT gene has yielded a carrier frequency of $1 / 60$ in this population grouping. Given that $>90 \%$ of galactosemia in this group is associated with this mutation, a newborn incidence of approximately $1 / 14400$ can be expected in the Cape Metropolitan region. This is in accord with the S135L carrier frequency data from the Northern regions of South Africa, which suggest a similar newborn incidence of approximately $1 / 22500$ [12]. The 
South African carrier frequencies for the S135L mutation are the highest reported so far and represent a significant concentration when contrasted with the frequency of $1 /$ 505 reported in African Americans [20].

The projected figure for black newborns for the year 2000, in the Cape Metropole was 25920 (RE Dorrington, UCT, Director Centre for Actuarial research); with the increasing urbanisation of the Cape Metropole this figure is certain to have increased in the subsequent years. This number translates into expected referrals of at least 1-2 galactosemics every two years; current referral of 1 every 5 yrs is significantly below this projection. Two opposing explanations are likely to account for this diagnostic shortfall. Patients, either go undetected and do not survive the neonatal period, or they do not present in the neonatal period. Some support for the latter explanation comes from the finding that the S135L mutation can be associated with a "mild" phenotype [8],[21], and it is conceivable that only the severe end of the S135L/S135L presentation spectrum, is attracting the attention of the medical fraternity in our region. It is likely that a measure of both possibilities is operative for our black patients.

The association of milder disease phenotypes with residual enzyme activity is now well described in the metabolic diseases literature. There are significant data to suggest that this is also the case with the S135L mutation and galactosemia. Subjects homozygous for the S135L mutation, although deficient in GALT activity in erythrocytes have approx. $10 \%$ residual activity and enzyme mass in liver, intestine and leucocytes [22],[23],[24]. This residual activity is also manifest by a whole body galactose oxidative capacity, which overlaps that of normal subjects when given a tracer challenge of ${ }^{13} \mathrm{C}$-galactose [25]. Clinical parallels would be the finding that S135L homozygotes have survived the neonatal period and have only been detected when later problems such as cataracts, developmental delay and poor school performance have been investigated [22], and that S135L homozygotes detected in new born screening programs appear to respond very well to dietary restriction of lactose / galactose [8].

\section{Conclusions}

The true incidence of galactosemia in the South African population is unknown, as newborn screening programmes have not been introduced. Reference laboratories such as our own indicate that the disorder is rare and probably has incidence data typical of those reported in the USA except for black South Africans. Carrier prevalence data in the black population suggests that the true incidence is much higher than that indicated by the numbers of patients referred for diagnostic workup. The reason for this discrepancy is unknown but may involve a lack of both detection and presentation in the neonatal period.
The delay in diagnosis revealed by our study indicates that improved clinical vigilance may lower the age at detection and improve the recognition of galactosemia in South Africa. We are unable to comment on the post-diagnosis clinical course of our S135L homozygotes as none were maintained on a galactose free diet for any length of time and all have been lost to follow up. We are also unable to comment on indications that the S135L mutation has less clinical impact than the Q188R mutation as most of our S135L homozygotes were born into a rural primary health-care environment and were thus diagnosed later than our Q188R homozygotes. Further research should focus on defining the phenotype / genotype relationships in South African patients to determine whether a milder clinical phenotype in S135L homozygotes does occur. Advances in understanding the pathogenesis of galactosemia may ultimately explain why despite early appropriate dietary intervention many patients develop severe neurological sequele and premature ovarian failure. Perhaps this will lead to further improvements to the outcome of the condition.

\section{Competing interests}

None declared

\section{Authors' contributions}

HE Henderson - Director of the DNA laboratory and wrote the manuscript.

F Leisegang - carried out the DNA testing.

R Brown - performed all the transferase and kinase assays.

B Eley - reviewed all folders and collated clinical data.

All authors have read the manuscript and expressed satisfaction with the content.

\section{Acknowledgements}

The project was funded by the Institute of Child Health, University of Cape Town

\section{References}

I. Segal S, Berry GT: Disorders of galactose metabolism. In: The metabolic and molecular bases of inherited diseases: (Edited by: Scriver CR, Beaudet AL, Sly WS, Valle D) McGraw-Hill, Inc. 1995, I:967-1 000

2. Waggoner D, Buist N, Donnell G: Long-term prognosis in galactosemia: Results of a survey of $\mathbf{3 5 0}$ cases. J Inherit Metab Dis 1990, 1 3:802-818

3. Raadsveld C, Klomp H: Thin-layer chromatographic analysis of sugar mixtures. J Cromatogr I971, 57:99

4. Beutler $E$, Mitchell M: New rapid method for the estimation of red cell galactose-I-phosphate uridyltransferase activity. $L a b$ Clin Med 1968, 72:527-532

5. Levy NS, Krille AF, Beutler E: Galactokinase deficiency and cataracts. Am J Opthal 1972, 74:4I-48

6. Reichardt JKV, Woo SLC: Molecular basis of galactosemia: mutations and polymorphisms in the gene encoding galactoseI-phosphate uridyl transferase. Proc Natl Acad Sci USA I99I, 88:2633-2637 
7. Reichardt JKV, Levy HL, Woo SL: Molecular characterisation of two galactosemia mutations and one polymorphism: implications for structure-function analysis of human galactose- Iphosphate uridyl transferase. Biochemistry 1992, 3 I:5430-5433

8. Lai K, Langley SD, Singh RH, Dembure PP, Hejlm LN, Elsas LJ: A prevalent mutation for galactosemia among black Americans. J Pediatr 1996, 128:89-95

9. Elsas EJ, Fridovich-Keil J, Leslie N: Galactosemia: a molecular approach to the enigma. Int Pediatr 1993, 8:101-109

10. Bernstein RE: Studies on metabolism and nutritional therapy of the galactosaeic infant and child. S Afr Med J 1965, 39: I I701173

II. Ojwang PJ, Manikum T, Deppe W: Galactosaemia in black South Africans. East Afr J Med 1999, 76:247-250

12. Manga N, Jenkins T, Jackson H, Whittaker DA, Lane AB: The molecular basis of transferase galactosemia in South African Negroids. J Inher Metab Dis 1999, 22:37-42

13. Novelli G, Reichardt JK: Molecular basis of disorders of human galactose metabolism: past, present, and future. Mol Genet Metab 2000, $71: 62-65$

14. Waisbren SE, Norman TR, Schnell RR, Levy HL: Speech and language deficits in early-treated children with galactosemia. J Pediatr 1983, I 02:75-77

15. Guerrero NV, Singh RH, Manatunga A, Berry GT, Steiner RD, Elsas LJ: Risk factors for premature ovarian failure in females with galactosemia. J Pediatr 2000, 137:833-84 |

16. Ng WG, Kaufman FR, Donnell GN, Wolff J, Allen RJ, Koritala S, Reichardt JK: Biochemical and molecular studies of 132 patients with galactosemia. Hum Genet 1994, 94:359-363

17. Elsas LJ, Friedovich-Keil JL, Leslie N: Galactosemia: a molecular approach to the enigma. Int Pediatr 1993, 8:101-109

18. Murphy M, McHugh B, Tighe O, Mayne P, O'Neill C, Naughton E, Croke DT: Genetic basis of transferase-deficiency galactosemia in Ireland and the population history of the Irish Traveller. Eur J Hum Genet 1999, 7:549-554

19. Applegarth DA, Toone JR, Lowry RB: Incidence of inborn errors of metabolism in British Columbia, 1969-1996 Pediatrics 2000, 105:e10

20. Susuki M, West C, Beutler E: Large-scale molecular screening for galactosemia alleles in a pan-ethnic population. Hum Genet 200I, 109:210-2I5

21. Baker L, Mellman WJ, Tedesco TA, Segal S: Galactosemia: symptomatic and asymptomatic homozygotes in one Negro sibship. J Pediatr 1966, 68:551-558

22. Segal S, Rogers S, Holtzapple PG: Liver galactose-I-phosphate uridyltransferase: activity in normal and galactosemic subjects. I Clin Invest 1971, 50:500-506

23. Rogers S, Holtzapple PG, Mellman WJ, Segal S: Characteristics of galactose-I-phosphate uridyltransferase in intestinal mucosa of normal and galactosemic humans. Metabolism 1970, 19:70I708

24. Landt M, Ritter D, Kent L, Benke PJ, Elsas LJ, Steiner RD RD: Black children deficient in galactose-I-phosphate uridyltransferase: Correlation of activity and immunoreactive protein in erythrocytes and leucocytes. J Pediatr 1997, 130:972-980

25. Berry GT, Singh RH, Mazur AT, Guerrero N, Kennedy MJ, Chen J, Reynolds R, Palmieri MJ, Klein PD, Segal S 2nd: Galactose breath testing distinguishes variant and severe galactose-I-phosphate uridyltransferase genotypes. Pediatr Res 2000, 48:323-328

\section{Pre-publication history}

The pre-publication history for this paper can be accessed here:

http://www.biomedcentral.com/1471-2431/2/7/prepub

Publish with BioMed Central and every scientist can read your work free of charge

"BioMedcentral will be the most significant development for disseminating the results of biomedical research in our lifetime." Paul Nurse, Director-General, Imperial Cancer Research Fund

Publish with BMC and your research papers will be:

- available free of charge to the entire biomedical community

- peer reviewed and published immediately upon acceptance

- cited in PubMed and archived on PubMed Central

- yours - you keep the copyright

Submit your manuscript here:

http://www.biomedcentral.com/manuscript/
BioMedcentral.com editorial@biomedcentral.com 